\title{
Importancia de la implementación de bibliotecas virtuales en la Universidad para complementar la educación virtual
}

\author{
Dr. José Antonio Legua Cardenas
}

En la nueva normalidad que estamos viviendo ocasionada por la enfermedad covid-19 se hace más urgente la necesidad de búsqueda de los recursos más idóneos para la enseñanza virtual entre otros la suscripción de bibliotecas virtuales, que tienen como principal ventaja el reducir distancias es decir que, a diferencia de las bibliotecas físicas y digitales, en las virtuales se puede obtener información en cualquier momento y en cualquier lugar lo que facilita reducir tiempos para cumplir tareas académicas y agilizar trabajos y proyectos de investigación. Las bibliotecas virtuales permiten la transmisión del conocimiento, el acceso a la información y favorecen la investigación.

Es evidente que es más fácil realizar las investigaciones vía internet, y obtener libros con una óptima información y de variadas temáticas. Se verifica que como la tecnología ha suplantado el uso de libros, pero de forma beneficiosa, para incentivar el uso de las bibliotecas virtuales y entender las diferencias entre virtuales y digitales, y su impacto en la educación universitaria y en otros niveles educativos.

Los recursos virtuales en el ámbito educativo se están infiltrando rápidamente en las universidades (Guerrero y Cervera, 2012), pasando del esquema tradicional de educación a uno digital. Uno de estos recursos ha sido la biblioteca virtual que se ha ido desarrollando e implementando como un medio para acercar el conocimiento a los universitarios, proporcionando beneficios en el acceso a información del medio académico y de investigación desde cualquier ubicación (Sánchez, 2007).

La revisión propia de la literatura de los últimos años, permite destacar la importancia que tiene en la actualidad la biblioteca virtual, la cual se ha convertido en una opción tecnológica predominante en el ámbito educativo por la enorme difusión de la producción científica que ésta representa (Veiga, 2001), haciéndola un almacén de conocimiento importante que debe propagarse a los alumnos a través de su uso continuo. Sin embargo, Babini, et al, (2007, p.61) nos advierte que "el mayor número de visitantes que recibe una biblioteca virtual se debe principalmente al tráfico que generan buscadores como Google y Yahoo, más que al conocimiento por parte de esos visitantes de los servicios que ofrece la biblioteca virtual".

\section{REFERENCIAS BIBLIOGRAFICAS}

Babini, Dominique; Vergara Florencia y Archuby, Gustavo. (2007). Estadísticas de usuarios en una biblioteca virtual. El caso de la biblioteca virtual de la red Clacso. El profesional de la información, 1(1):57-61 enero-febrero

Guerrero, José y Cervera, Mercé. (2012). El cambio organizacional en la universidad a través del uso de los campus virtuales desde la perspectiva de los estudiantes. Revista de Medios de Comunicación, 40: 75-88.

Sánchez-García, Jaime. (2007). La falacia de la ampliación de la cobertura educativa mediante la utilización de las NTIC y la educación a distancia en la educación superior en México. Revista Iberoamericana de Educación, 45:123140.

Veiga, Jorge. (2001). La biblioteca virtual en salud (BVS): Una apuesta por la difusión de la producción científica española y latinoamericana en colaboración con la OPS/OMS. Rev. Esp. Salud Publica, 75(4): 277-280 julio/agosto. 